\title{
SERUM HEXOSAMINE LEVELS IN HEALTH AND DISEASE*
}

\author{
BY \\ SARA WEIDEN $\dagger$ \\ From the Clinical Research Unit of the Walter and Eliza Hall Institute of Medical Research and \\ the Royal Melbourne Hospital, Victoria, Australia
}

(RECEIVED FOR PUBLICATION MAY 2, 1957)

Hexosamine is a normal component of serum mucoprotein and its level may be regarded as an index of total mucoprotein which includes $\alpha, \beta$, and $\gamma$ globulins, fibrinogen, " seroglycoid," and "seromucoid." Interest in seromucoids was greatly enhanced when it was found by West and Clarke (1938) and others that in acute and chronic infections, in malignancy, and in a number of endocrine disturbances, the hexosamine and inferentially the mucoid fractions increased above the normal range.

Raised serum hexosamine levels have been found in patients suffering from infection and disseminated malignant disease (West and Clarke, 1938 ; Weisbrod, 1950), in rheumatic fever (Rosenberg and Schloss, 1949 ; Kelley, 1952), in rheumatoid arthritis and asthma (Jiménez Díaz, Aguirre, and Arjona, 1953), and in pneumonia (Nilsson, 1937 ; Faber, 1948). The plasma hexosamine level also increases after extensive trauma (Schlamowitz, de Graff and Schubert, 1950; Boas and Peterman, 1953 ; West and Clarke, 1938).

In this paper, a systematic study has been made of serum hexosamine levels both in normal people and in a wide range of pathological conditions, in order to determine whether the presence of a high serum hexosamine level could be used as an indication of certain pathological states.

\section{Method}

Although numerous modifications of the ElsonMorgan (1933) method for the estimation of hexosamine have been described (Palmer, Smyth, and Meyer, 1937 ; Blix, 1948 ; Johnston, Ogston, and Stainer, 1951; Boas, 1953), none seemed entirely satisfactory for the handling of clinical material, where it is essential to be able to deal with large numbers of specimens without any significant loss in accuracy. Eventually a modification incorporating

\footnotetext{
* Submitted in part for the degree of Ph.D., University of Melbourne.

+ Working with the aid of a grant from the National Health and Medical Research Council of Australia.
}

several methods was established and successfully employed as follows :

Solutions.-All solutions were prepared freshly on the day of use.

Ehrlich Reagent.-Recrystallized p-dimethylaminobenzaldehyde, $1.5 \mathrm{~g}$., was dissolved in $75 \mathrm{ml}$. of $95 \%$ redistilled ethyl alcohol to which $25 \mathrm{ml}$. of concentrated $\mathrm{HCl}$ was then added and made up to a final volume of $500 \mathrm{ml}$. with $95 \%$ ethyl alcohol. This gives the optimum $5 \%$ concentration of acid recommended by Elson and Morgan (1933).

Acetylacetone Solution.-Concentrated acetylacetone (B.D.H.), $2 \mathrm{ml}$., was diluted with $0.75 \mathrm{~N} \mathrm{Na}_{2} \mathrm{CO}_{3}$ to $50 \mathrm{ml}$. This guarantees a final $p \mathrm{H}$ for the condensation reaction of approximately 9.7 .

Standard Glucosamine Hydrochloride Solution.-A stock solution of glucosamine hydrochloride (200 mg. glucosamine in $100 \mathrm{ml}$. of water) was used to prepare solutions containing $20,40,60,80,100,120$, and $140 \mathrm{mg}$. glucosamine per $\mathrm{ml}$.

Determination of Hexosamine.-One millilitre of $4 \mathrm{~N} \mathrm{HCl}$ was added to $1 \mathrm{ml}$. serum and the sample hydrolysed in a boiling water bath for six hours.

After cooling, the sample was neutralized with $4 \mathrm{~N} \mathrm{NaOH}$ to $p \mathrm{H} 6.5$ using "universal" indicator paper, then transferred by means of a pipette to a $20 \mathrm{ml}$. standard flask, the tube being washed with several lots of distilled water. It was then made up to a final volume of $20 \mathrm{ml}$. and filtered through Whatman No. 42 filter paper.

To $1 \mathrm{ml}$. of filtrate in a special pyrex test tube ( 8 in. $\times \frac{3}{4}$ in.) was added $1 \mathrm{ml}$. acetylacetone solution and the sides of the tube washed down with $1 \mathrm{ml}$. distilled water. The tube was stoppered with a longnecked sealed glass ampoule containing 2-3 ml. water. After heating 15 minutes in a boiling water bath, the rack of such tubes was transferred to an ice bath for 10 minutes.

Acetylacetone solution was also added to $1 \mathrm{ml}$. samples of suitable standard solutions and these tubes were heated at the same time as the unknowns. All the tubes were placed in the same metal rack so that they were simultaneously plunged and removed from the boiling water. 
When cool, the tubes were removed to a wooden rack and $10 \mathrm{ml}$. Ehrlich solution added to each and then shaken.

A "blank" was treated similarly.

After standing 30 minutes in the dark at room temperature, the colour intensity produced was read in a photoelectric colorimeter using a green filter. A standard curve was prepared and the concentration of the unknowns determined. This method does not differentiate between glucosamine and galactosamine: it gives the total hexosamine content of the hydrolysates.

\section{Results}

The failure of the ingestion of food to affect the serum hexosamine level in three normal individuals is shown in Table $I$.

TABLE I

EFFECT OF FOOD ON SERUM HEXOSAMINE LEVELS

\begin{tabular}{|c|c|c|c|c|c|}
\hline \multirow{2}{*}{ Case } & \multicolumn{5}{|c|}{ Hexosamine (mg. \%) } \\
\hline & Fasting & \multicolumn{4}{|c|}{ Time after High-protein-carbohydrate Meal } \\
\hline & & 1 Hour & 2 Hours & 3 Hours & 4 Hours \\
\hline $\begin{array}{ll}\text { W. } & \ldots \\
\text { W.s. } & \ldots\end{array}$ & $\begin{array}{r}110 \\
90 \\
106\end{array}$ & $\begin{array}{r}119 \\
94 \\
105\end{array}$ & $\begin{array}{r}104 \\
92 \\
97\end{array}$ & $\begin{array}{r}108 \\
93 \\
97\end{array}$ & $\begin{array}{l}115 \\
109\end{array}$ \\
\hline
\end{tabular}

A high-protein, high-carbohydrate meal had no significant effect on serum hexosamine levels for a period of four hours following the meal. This had previously been shown in one individual by
Shetlar, Foster, Kelly, and Everett (1948). According to Boas and Peterman (1953), fasting $\stackrel{\vec{S}}{\stackrel{+}{+}}$ in rats does not lower the hexosamine level for the first 24 hours.

\section{Variation of Serum Hexosamine Levels}

The variation in the hexosamine level in an individual over a period of several weeks is only small, as is shown in Table II, which records serum hexosamine levels in six normal individuals at weekly intervals for several weeks.

TABLE II

WEEKLY SERUM HEXOSAMINE IEVELS IN NORMAL INDIVIDUALS

\begin{tabular}{|c|c|c|c|c|c|}
\hline \multirow{3}{*}{ Case } & \multicolumn{5}{|c|}{ Hexosamine (mg. \%) } \\
\hline & \multicolumn{5}{|c|}{ Time in Weeks } \\
\hline & 1 & 2 & 3 & 4 & 5 \\
\hline $\begin{array}{ll}\text { I.W. } & \cdots \\
\text { L.T. } & \cdots \\
\text { F.P. } & \cdots \\
\text { F.J. } & \cdots \\
\text { K.G. } & \cdots \\
\text { F.S. } & \cdots\end{array}$ & $\begin{array}{r}100 \\
96 \\
96 \\
86 \\
85 \\
100\end{array}$ & $\begin{array}{r}96 \\
95 \\
92 \\
87 \\
87 \\
106\end{array}$ & $\begin{array}{r}100 \\
96 \\
96 \\
86 \\
92 \\
101\end{array}$ & $\begin{array}{l}96 \\
96 \\
94 \\
88 \\
97\end{array}$ & $\begin{array}{l}84 \\
98\end{array}$ \\
\hline
\end{tabular}

Serum Hexosamine Levels in Normal Subjects and in Various Pathological Conditions

Serum hexosamine determinations were carried out on 191 individuals and the results are expressed graphically in Fig. 1.

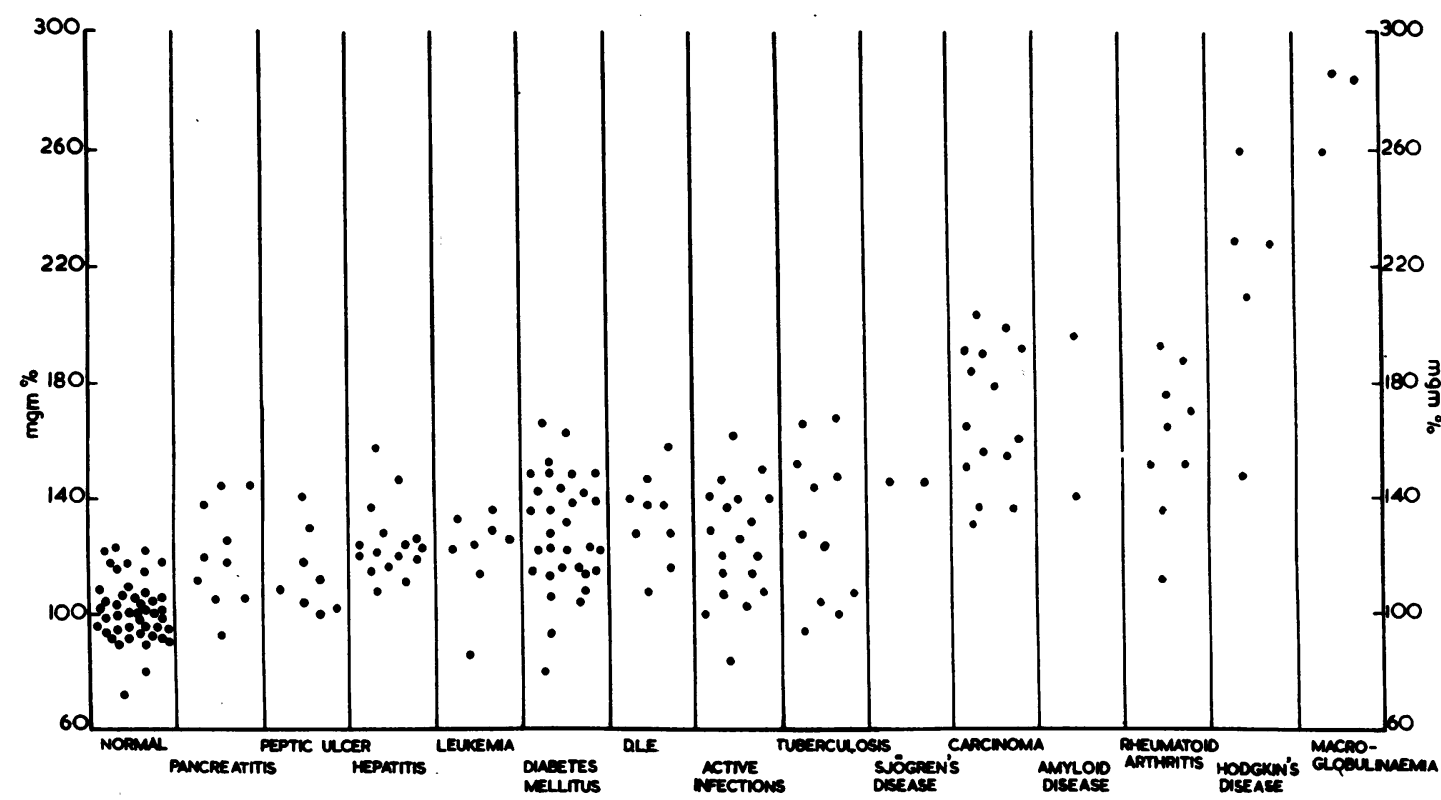

FIG. 1.-Serum hexosamine levels in normal and pathological conditions. 
Normal Serum Hexosamine.-Normal serum hexosamine levels have been reported by a number of workers and cover a wide range (Table III).

TABLE III

HEXOSAMINE LEVELS IN NORMAL INDIVIDUALS

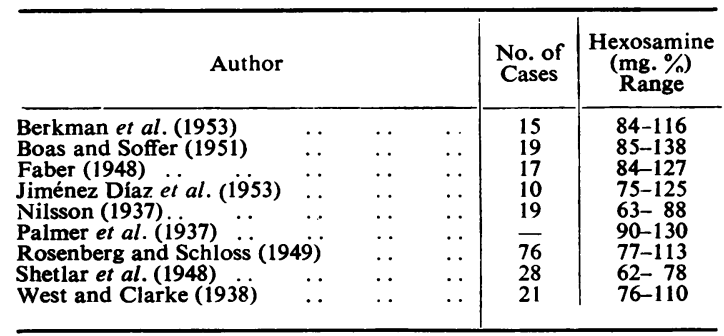

In the present investigation blood was obtained from 45 normal individuals-staff members, nurses, and medical students. The mean average value was found to be $101.5 \mathrm{mg} . \%$ with a standard deviation of $\pm 11.0 \mathrm{mg}$. $\%$ and the range 80-124 mg. \% ( \pm 2 S.D.).

Pancreatitis.-Ten patients suffering from pancreatitis proved biochemically, and in some instances at operation, were found to have normal serum hexosamine levels. In three instances the values were above the upper range of normal, but not to any significant extent.

Peptic Ulcer.-All the eight peptic ulcer patients investigated had values in the normal range.

Liver Disease.- Of 16 patients with liver disease, two had acute infectious hepatitis, eight chronic infectious hepatitis, and five cirrhosis due to nutritional causes. Normal values were obtained in all but two patients-one with chronic infectious hepatitis who also showed lupus erythematosus cells in the blood (Mackay, Taft, and Cowling, 1956), and the other a patient with nutritional cirrhosis of the liver.

Using the turbidimetric method of Kunkel, Ahrens, and Eisenmenger (1948), the $\gamma$ globulin content of the serum was determined in 15 of the patients with liver disease, but no close correlation could be shown between serum $\gamma$ globulin and the hexosamine levels in these patients (Fig. 2).

Acute Infections.-In 20 patients with varying acute infections, there was a wide range of hexosamine levels from normal to $162 \mathrm{mg} . \%$ in a patient with pneumonia.

Tuberculosis.-Normal values were obtained in six of the 11 patients with active tuberculosis (eight pulmonary, two renal, and one tuberculous meningitis). It was found in the pulmonary cases

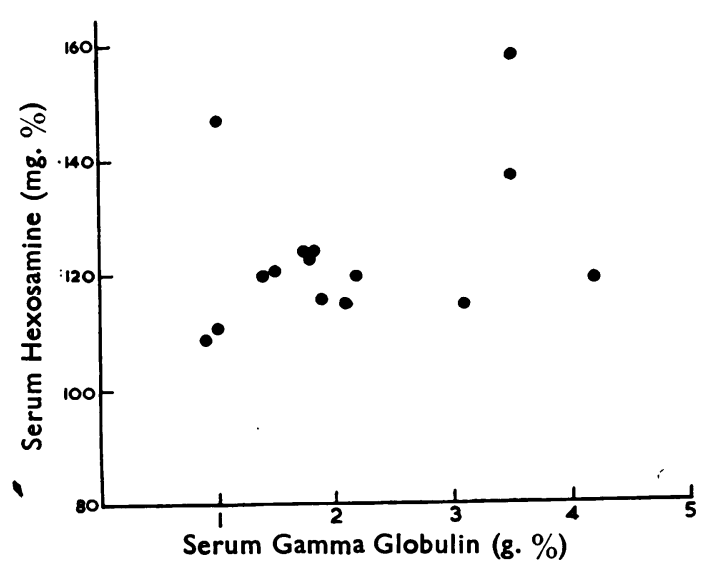

FIG. 2.-Chart showing the lack of correlation between serum hexosamine and gamma globulin levels in liver disease.

that the serum hexosamine increased with the severity of the disease. -The highest value of $168 \mathrm{mg} . \%$ was obtained in a patient with extensive active pulmonary tuberculosis.

Systemic Lupus Erythematosus. - Increased values were obtained in six of the nine patients with lupus erythematosus tested; the remaining three were normal. The values ranged between 128 and $158 \mathrm{mg} . \%$ and are lower than those obtained by Boas and Soffer (1951) in this disease. As with the cases of liver disease, there was no close correlation between the hexosamine and $\gamma$ globulin content of the serum in 17 determinations carried out on nine patients (Fig. 3). This is not in agreement with Boas and Reiner (1951), who claimed that the serum hexosamine in systemic lupus erythematosus was a reasonable index of the amount of circulating $\gamma$ globulin in these patients.

Diabetes Mellitus. - The serum hexosamine level was determined in 32 patients suffering from diabetes mellitus of varying degrees of severity. Eighteen of the patients had values above the upper range of normal, the highest value being $166 \mathrm{mg} . \%$. Raised values were present in both old and young diabetics, and irrespective of whether the control of the diabetes with insulin had been good or poor. This is in keeping with the findings of Taft, Finckh, and Joske (1954) which suggested that the lesions of the Kimmelstiel-Wilson syndrome would occur irrespective of whether there is efficient insulin therapy. Taft et al. (1954) used needle biopsies of the kidney in their studies.

In the present survey, 12 of the 26 diabetic patients in whom renal disease was not evident as 


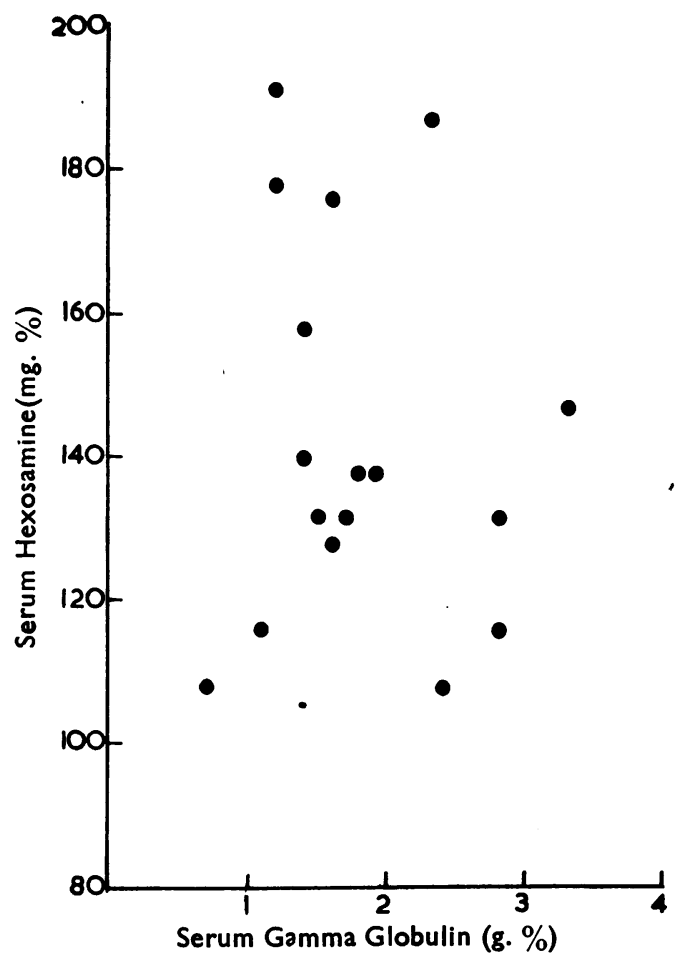

Fig. 3.-Chart showing the lack of correlation between serum hexosamine and gamma globulin levels in systemic lupus erythematosus.

yet had raised serum hexosamine. However, only four of the six patients with diabetic renal disease confirmed by renal biopsy had raised serum hexosamine values.

Leukaemia.-In six patients with chronic lymphatic leukaemia and in two with chronic myeloid leukaemia, there was only a slight rise in the hexosamine level. The highest values, 129, 133, and $136 \mathrm{mg} . \%$, were in patients with chronic lymphatic leukaemia.

Carcinoma.-High serum hexosamine values were obtained in all but one of the 15 patients with carcinoma. In four instances the value was over $190 \mathrm{mg} . \%$. The mean average value was $163 \mathrm{mg} . \%$. Similar increases have been reported by other workers (Greenspan, Lehman, Graff, and Schoenbach, 1951; West and Clarke, 1938 ; Jiménez Díaz et al., 1953 ; Faber, 1948).

Rheumatoid Arthritis.-Only one of the nine patients with rheumatoid arthritis had a serum hexosamine level within the normal range. The mean average value was $160 \mathrm{mg} . \%$ and the range $112-193 \mathrm{mg} . \%$. This agrees with the previous findings of Jiménez Díaz et al. (1953) and Shetlar, Payne, Bullock, Patrick, Hellbaum, and Ishmael (1953).

Sjögren's Disease.-An identical value of $146 \frac{\overline{\bar{c}}}{\bar{c}}$ mg. \% was obtained in two patients with Sjögren's $\mathbb{\Phi}$ disease, which is characterized by diminished lacrimal and oral secretions and arthritis.

Amyloid Disease.-Although amyloid disease is $\stackrel{\circ}{\circ}$ now a comparatively rare disease, serum was $\vec{\omega}$ obtained from two cases in which the diagnosis? was finally confirmed at post-mortem examina $\frac{?}{0}$ tion. The serum hexosamine values were elevated $\vec{A}$ to 141 and $196 \mathrm{mg} . \%$ respectively.

Hodgkin's Disease.-Serum was obtained from $\vec{V}$ five patients with Hodgkin's disease. Very high ${ }_{\mathrm{O}}$ values were obtained in four of the cases, namely, $210,228,229$, and $260 \mathrm{mg} . \%$. The remaining patient had a raised value of $148 \mathrm{mg} . \%$.

Macroglobulinaemia.-The highest values for ${ }^{\supset}$ serum hexosamine, 260,284 , and $286 \mathrm{mg}$. \%, were $\vec{c}$ obtained in three patients suffering from macro- $\infty$ globulinaemia, a disease first described in Sweden by Waldenström (1944) and characterized by an excessive production of serum globulins of an abnormally high molecular weight, detectable by ultracentrifugal analysis of serum. Macro- $\frac{\mathbb{Q}}{\mathscr{Q}}$ globulinaemia resembles multiple myeloma by $\overrightarrow{\vec{F}}$ reason of abnormal globulin production, but the histopathology is suggestive of a lymphocytic $\frac{3}{5}$ neoplasia, either chronic lymphatic leukaemia or lymphosarcoma. It has been suggested (Mackay Taft, and Woods, 1957) that the basic process? may, in fact, be a lymphosarcoma with macro-globulin synthesis, the result of a somatic muta tion in the tumour cell line. Occasionally, however, macroglobulinaemia is associated with other types of neoplasm, and the condition may even? exist in the absence of any apparent disease pro- $\rightarrow$ cess (Laurell, Laurell and Waldenström, 1957).

\section{Discussion}

Hexosamine is a normal component of serumo mucoprotein and its determination is an indexcu of the total mucoprotein (Rimington, 1931, 1940 ? Mehl, Humphrey, and Winzler, 1949; Smitho Brown, Weimer, and Winzler, 1950; Schmid 1953). It is also a component of various globulin? fractions (Blix, Tiselius, and Svensson, 1941 ; Boaș and Reiner, 1951 ; Boas, 1955 ; Werner, 1951). If the present investigation, the level for serum hexose amine was found to be between 80 and $124 \mathrm{mg} . \%$ in 45 normal individuals, and this agrees witto values reported in the literature (Faber, 1948 i 
Palmer et al., 1937; Rosenberg and Schloss, 1949 ; Berkman, Rifkin, and Ross, 1953 ; Jiménez Díaz et al., 1953). The serum hexosamine level remained constant over a period of several weeks, and was not significantly altered by food.

Pancreatitis, peptic ulcer, and liver disease had no effect on the serum hexosamine level which was, however, significantly increased in those diseases associated with bacterial infection and tissue proliferation. Thus moderately raised values were obtained in patients with pneumonia and tuberculosis and the height of the increase corresponded to the severity of the disease. Increased values were also obtained in patients with systemic lupus erythematosus, but no correlation could be found in these patients between the $\gamma$ globulin and serum hexosamine level as reported by Boas and Reiner (1951). The same lack of correlation with $\gamma$ globulin was found in the patients with liver disease.

Raised serum hexosamine values were obtained in approximately $50 \%$ of patients with diabetes mellitus. The high values were in patients with renal disease and in 12 of the 28 patients without renal disease. The nature of diabetic renal disease remains obscure. Abnormal protein material, which may line endothelial surfaces and infiltrate blood vessel walls, is deposited in the kidney. The staining properties of this material suggest that it contains protein, polysaccharide, and some lipid. It would seem that in some cases of diabetes mellitus there is an underlying metabolic defect involving hexosamine metabolism which produces an increase in mucoprotein in the blood and its deposition in the kidney. It is not yet known whether the deposition comes first and causes the renal damage or whether there is a preexisting renal damage. Raised hexosamine values were obtained in both young and old diabetics and irrespective of whether the control of the diabetes with insulin and diet had been good or poor. Similar findings were obtained by Taft et al. (1954) in their needle biopsy study of renal lesions in the Kimmelstiel-Wilson syndrome. Isotope studies in animals indicated that the mucosubstances of the body are in a continuous state of turnover (Schiller, Mathews, Jefferson, Ludowieg, and Dorfman, 1954 ; Schiller and Dorfman, 1955).

The biosynthesis of mucosubstances has considerable importance in pathological conditions, particularly those where extensive proliferation of cells occurs. Human and animal synovial membrane grown in tissue culture produced hyaluronic acid (Kling, Levine, and Wise, 1955: Grossfeld,
Meyer, and Godman, 1955), a hexosamine-containing mucopolysaccharide which is the main constituent of the ground substance of connective tissue (Meyer and Rapport, 1951). Raised serum hexosamine therefore can be regarded as a nonspecific index of tissue destruction, or of proliferation and repair. In the present study high values for serum hexosamine were obtained in patients with Hodgkin's disease and carcinoma, where proliferation and breakdown of tissue existed with probable shedding of the breakdown products into the tissue spaces and absorption into the blood stream. Thus the determination of the serum hexosamine level is a valuable aid in the differential diagnosis of Hodgkin's disease from chronic infections where values are not very high.

Increased synthesis of mucopolysaccharides in the ground substance of connective tissue in rheumatoid arthritis could account for the high serum hexosamine values obtained in the patients with this disease and for the pain and stiffness of the joints. As cortisone will inhibit connective tissue formation (Layton, 1951a, 1951b), this may be responsible for the improvement in patients with rheumatoid arthritis when treated with this compound.

The highest values for serum hexosamine obtained in this study were in patients suffering from macroglobulinaemia as opposed to normal values in leukaemia. In macroglobulinaemia there is a synthesis of abnormal serum globulins, macroglobulins, which are probably elaborated by the reticulo-endothelial plasmacyte system (Mackay. Eriksen, Motulsky, and Volwiler, 1956).

\section{Summary}

(1) The determination of the hexosamine level of serum is an index of its total mucoprotein content.

(2) The range for serum hexosamine in 45 normal individuals was found to be $80-124$ $\mathrm{mg} . \%$ with a mean average value of $101.5 \mathrm{mg} . \%$ $\pm 11 \mathrm{mg} . \%$.

(3) Ingestion of food did not alter serum hexosamine levels, which remained constant over a period of weeks as shown by random sampling in normal controls.

(4) The serum hexosamine level was normal in cases of peptic ulcer, pancreatitis, liver disease, and leukaemia.

(5) It was moderately raised in active infections such as tuberculosis, pneumonia, and bacterial endocarditis. 
(6) Markedly increased values were obtained in systemic lupus erythematosus, rheumatoid arthritis, carcinoma, amyloid disease, Hodgkin's disease, and macroglobulinaemia.

(7) The high level of serum hexosamine in Hodgkin's disease and macroglobulinaemia can be used as an aid in the diagnosis of these diseases.

(8) No correlation could be found between serum hexosamine and $\gamma$ globulin levels in patients with hepatitis or systemic lupus erythematosus.

(9) In diabetes mellitus more than half of the patients showed some increase in serum hexosamine levels. This rise could not be correlated with the efficiency of the control of the hyperglycaemia by insulin.

My thanks are due to Dr. H. P. Taft, Royal Melbourne Hospital, Dr. D. Rosenthal, Deputy Director of Tuberculosis in Victoria, and Dr. Ian Mackay for supplying blood samples, and to Dr. Ian Wood for his help and encouragement in the preparation of this paper.

\section{REFERENCES}

Berkman, J., Rifkin, H., and Ross, G. (1953). J. clin. Invest., 32, 415. Blix, G. (1948). Acta chem. scand., 2, 467.

- Tiselius, A., and Svensson, H. (1941), J. biol. Chem., 137, 485. Boas, N. F. (1953). Ibid., 204, 553 .

- (1955). Proc. Soc. exp.Biol. (N.Y.), 90, 4.

-

-.. and Reiner, M. (195i). J. clin. Endocr., 11, 890.

—— and Soffer, L. J. (1951). Ibid., 11, 39.

Elson, L. A., and Morgan, W. T. J. (1933). Biochem. J., 27, 1824.
Faber, M. (1948). Acta med. scand., Suppl. 206, 351.

Greenspan, E. M., Lehman, I., Graff, M. M., and Schoenbach, E. B. (1951). Cancer, 4, 972.

Grossfeld, H., Meyer, K., and Godman, G. (1955). Proc. Soc. exp. Biol. (N.Y.) $, 88,31$.

Jiménez Díaz, C., Aguirre, M., and Arjona, E. (1953). Bull. Inst. med. Res. Univ. Madr., 6, 137.

Johnston, J. P., Ogston, A. G., and Stanier, J. E. (1951). Analyst. 76, 88 .

Kelley, V. C. (1952). J. Pediat., 40, 413.

Kling, D. H., Levine, M. G., and Wise, S. (1955). Proc. Soc. exp. Biol. (N.Y.), 89, 261 .

Kunkel, H. G., Ahrens, E. H., and Eisenmenger, W. J. (1948). Gastroenterology, 11, 499.

Laurell, C. B., Laurell, H., and Waldenström, J. (1957). Amer. J. Med., 22, 24.

Layton, L. L.(1951a). Arch. Biochem. Biophys., 32, 224 (1951b). Proc. Soc. exp. Biol. (N.Y.), 76, 596.

Mackay, I. R., Eriksen, N., Motulsky, A. G., and Volwiler. W. (1956). Amer. J. Med., 20, 564

Taft, L. I, and Cowling, D. C. (1956), Lancet, $2,1323$.

- and Woods, E. F. (1957). Brit. med.J., 1, 561.

Mehl, J. W. Humphrey, J., and Winzler, R. J. (1949). Proc. Soc exp. Biol. (N.Y.), 72, 106.

Meyer, K., and Rapport, M. M. (1951). Science, 113, 596

Nilsson, I. (1937). Biochem. Z., 291, 254.

Palmer, J. W., Smyth, E. M., and Meyer, K. (1937). J. biol. Chem., 119,491 .

Rimington, C (1931), Biochem. J., 25, 1062

(1940). Ibid., 34, 931 .

Rosenberg, C., and Schloss, B. (1949). Amer. Heart J., 38, 872

Schiller, S., and Dorfman, A. (1955). Biochim. Biophvs. Acta, 16, 304 Mathews, M. B., Jefferson, H., Ludowieg, J., and Dorfman, A (1954). J. biol. Chem., 211, 717.

Schlamowitz, S. T., Graff, A. C. de, and Schubert, M. (1950). Circulation, 1, 822.

Schmid, K. (1953). J. Amer. chem. Soc., 75, 2532.

Shetlar, M. R., Foster, J. V., Kelly, K. H., and Everett, M. R. (1948). Proc. Soc. exp. Biol. (N.Y.), 69, 507.

- Payne, R. W., Bullock, J. A., Patrick, D. R., Hellbaum, A. A. and Ishmael, W. K. (1953). J. clin. Invest., 32, 1208.

Smith, E. L., Brown, D. M., Weimer, H. E., and Winzler, R. J. (1950) J. biol. Chem., 185, 569.

Taft, H. P., Finckh, E. S., and Joske, R. A. (1954). Aust. Ann. Med. 3, 189 .

Waldenström, J. (1944). Acta med. Scand., 117, 216

Weisbrod, F. G. (1950). J. Lab. clin. Med., 35, 408.

Werner, I. (1951). Acta chem. scand., 5, 1396.

West, R., and Clarke, D. H. (1938). J. clin. Invest., 17, 173. 